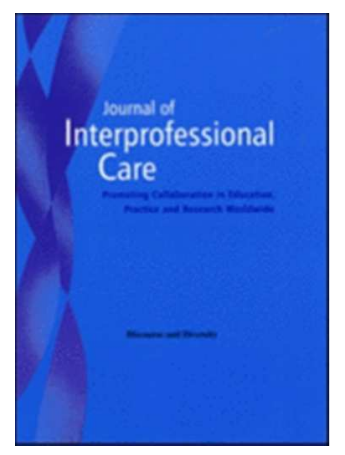

Collaborative practices between correctional and mental health services in Norway: expanding the roles and responsibility competence domain

\begin{tabular}{|r|l|}
\hline Journal: & Journal of Interprofessional Care \\
\hline Manuscript ID & CJIC-2015-0431.R2 \\
\hline Manuscript Type: & Article \\
\hline Keywords: & mental health, criminal justice, offenders, Norway, prison \\
\hline \multicolumn{2}{|c}{} \\
\hline
\end{tabular}

SCHOLARONE

Manuscripts 
Figure 1: Interrelated themes describing responsibility distribution in collaborative practice between the MHS and CS. 


\title{
Collaborative practices between correctional and mental health services in Norway: expanding the roles and responsibility competence domain
}

\begin{abstract}
Internationally, mental illness is high in prison populations. Collaboration between the correctional services (CS) and mental health services (MHS) is required to address this. Little is known of the collaborative processes in this context, however. This paper presents the findings of a study exploring the characteristics of collaborative practices between the MHS and CS in a Norwegian context. A purposeful sample $(n=12)$ of MHS and CS leaders was recruited from one region in Norway. Taking a generic qualitative approach, semistructured interviews with each participant explored specific structures that promoted collaboration, the nature of collaborative relationships and factors that facilitated or constrained these. The study indicated that leader are exercised by one dimension of collaborative practice in particular, namely the distribution of responsibility for the care of the offender across systems. This activity is mediated by highly complex external structures as well as the individual characteristics of the professionals involved. They speculate that professionals and organisations who fail to take responsibility for the offender as expected, may be constrained from doing so by resource limitations, logistical issues and poor attitudes towards the offender population. Based on these findings, this study suggests that the MHS and CS workforce would benefit from a great knowledgeability of the roles and responsibility domains of collaborative practice. Improving competence in the workforce in this area would achieve this. However, competency frameworks that address this domain are currently limited. Recommendations on how to extend the remit of this domain, in light of the current findings, are provided.
\end{abstract}

\section{Introduction}

Although Norway's reoffending rates are comparatively low, $20 \%$ of offenders will receive a new conviction within two years (Kristoffersen, 2013). Mental illness is one of the risk factors associated with this reoffending (Sapouna, 2015; Chang, Larsson, Lichtenstein, \& Fazel, 2015; Armstrong, 2012; Skeem \& Peterson, 2011), of concern as mental illness is high in prison populations internationally, including Norway, where $92 \%$ of offenders have some form of mental health issue (HelseSørØst, 2014). Mental illness does not occur in isolation, however, being closely intertwined with a range of childhood stressors and other 
welfare deficiencies (Friestad \& Kjelsberg, 2009). Reducing reoffending hinges on mental health being treated in tandem with other welfare needs.

Correctional Services (CS) increasingly take a rehabilitation and reintegration approach as a more holistic and humanitarian to tackling the challenge of reoffending. This is an alternative to a punishment or deterrent related focus. Hereby the CS explore ways through which offenders can be supported to address their current health and welfare needs and sustain their desistance behaviours in the longer term (Armstrong, 2012).

The focus on reintegration is put into practice in the Norwegian context through the normality principle that stresses the importance of offenders receiving the same services as those available to the wider population (Norwegian Ministry of Justice and the Police, 2008). Nurses and prison doctors, employed by the local municipality, and mental health professionals employed by specialised mental health services (MHS) in regional hospitals, work within the prison offering mental health and substance misuse services to offenders on a part or full time basis. Further, a reintegration guarantee is in place (Sverdrup, 2013; Armstrong 2012;) where offenders upon release, have the right to an offer of employment, education, suitable housing accommodation, some type of income, medical services, addiction treatment services and debt counselling. Prisons and multiple health and welfare services work together to deliver this and co-ordination posts (tilbakeføringkoordinatorTFK) have been introduced to coordinate this collaborative activity at a systems level (Sverdrup, 2013). This reflects recommendations provided Europe-wide by the Justice Cooperation Network, (2012) that highlighted collaborative working as key to reducing reoffending. Despite these recommendations, little is known about what characterises collaborative practice in this context.

\section{Dimensions of Collaborative practice}

Collaborative practice between health and welfare services more generally is a multidimensional and multilevel construct (Ødegård 2006, Willumsen, 2008). At a structural level, collaborative practice is an external feature of service organisation: a balance between ways in which units are differentiated from each other (e.g. the specialist sections or departments the organisation is divided into and the type of personal employed within them) versus the structures that integrate or establish continuity between these units (e.g. interprofessional teams or team meetings). This differentiation and integration 
occurs both within and between organisations (WIllumsen, 2008). Stones (2005) suggests that these external structures impact on individual agency, in this instance a professional's collaborative practice. The latter is mediated also by structures internal to the individual professional. Perceptions of collaborative practice are one such internal structure and may include the way a professional views the professional power differences between collaborators (Ødegård 2006).Although the longer term impact of collaborative practice on population health and the quality of care and patient experiences are difficult to establish (Brandt, Lutfiyya, King, \& Chioreso, 2014), improving collaborative practice, as a focus of organisational quality improvement, has been linked to positive service user outcomes including reduced length of patient hospital stay, lower costs, improvement in the way drugs are prescribed and increased audit activity (Zwarenstein, Goldman, \& Reeves, 2009). In the innovation literature, the space between different groups of collaborator, demarcated by professional, departmental or organisational boundaries, is described as a highly productive area where a diversity of ideas meet and generate socially innovative solutions to practice problems (Vangen \& Huxham, 2013). However, these can also be challenging places to negotiate (Akkerman and Bakker, 2011; Edwards, 2011).

Improving collaborative practice within this boundary space between the MHS and CS is specifically important not only because of its potential in the longer term to improve offender outcomes but also because of its shorter term potential to enable service leaders and front line workers alike to generate joint solutions to the rapidly changing needs of the offender population. Bond \& Gittell, (2010), for example, find links between collaborative practices between support agencies and reoffending rates. Other than these authors, however, collaborative practices between the MHS and CS is under-investigated despite an equal need for the CS and MHS to combine forces to develop ways of working that are cost effective and deploy resources differently and effectively (Hean, Willumsen \& $\varnothing$ degård, 2015). This paper therefore presents findings of a qualitative arm of a wider study that explored the MHS and CS leaders' perspectives of the characteristics of collaborative practices between their services in a Norwegian context (http://cordis.europa.eu/project/rcn/188119_en.html). The paper reports a dominant issue arising from interviews that related to professional responsibility and how this is negotiated between professionals across the MHS and CS boundary. 


\section{Method}

The research described in this paper is the first and exploratory phase of a wider study that explored collaborative practices between the MHS and CS in a sequential mixed methods design (Tashakkori and Teddlie 2003).

\section{Sample}

To explore the characteristics of collaborative practices between mental health and correctional services in a Norwegian context, a purposeful sample $(n=12)$ (Patton, 2002) of administrative leaders from both the MHS and CS were recruited from one of the five regions into which the Norwegian CS are divided up nationally. Participants were recruited on the basis of their key leadership status in the region and their ability to give a rich and heuristic overview of each system and the collaborations between them. Although representation from both the CS and the MHS was required, there was an element of snowballing associated with the sampling as Interviewees were asked to identify other relevant leaders in the course of their interview (Patton, 2002).

The sample comprised of six female and six male leaders. Regional leaders in the correctional services, prison leaders and probation leaders $(n=5)$ were represented, as were leaders in general prison health services $(n=2)$, prison social services $(n=1)$ and specialised mental health services $(n=2)$. Individuals perceived to have overview of both the MHS and CS systems were also included (representatives from county offices and a senior researcher in the field $(n=2)$. Professionally these leaders were trained as lawyers $(n=3)$, social workers $(n=4)$, nurses $(n=2)$, a medical doctor, psychiatrist and family therapist.

\section{Data collection}

A critical realist stance was taken in the study with the perspective that whilst a reality of collaborative practice between systems existed, this reality is individually interpreted by each individual (Bhaskar, 2008; Stones, 2005). Empirically, the experiences of leaders in the MHS and CS of the external reality of collaboration and structures that mediate collaboration were explored qualitatively using semi-structured interviews as the method of data collection. The interview guide explored inductively how the MHS and CS work together in practice. Specific prompts related to the range of services involved, specific 
structures in place to promote collaboration, the nature of relationships between services and what facilitated or constrained how they worked together.

The interviewer kept a reflective diary (Patton 2002) on the conduct of the interview. The interviews were at the workplace of Interviewees, 1-11/2 hours in duration, except in one instance where a respondent chose to extend the duration of the interview voluntarily. The interviews were conducted in English by the first author but together with a Norwegianspeaking colleague (second author) to clarify language issues arising. In two cases, Interviewees requested a colleague to attend to assist with language issues.

\section{Analysis}

Interviews were transcribed verbatim and analysed in parallel to data collection in order that emerging themes could be more fully explored in future interviews. Interview tapes, transcripts and quotations were anonymised. Analysis was conducted QSR NVivo 10 to manage the data. An inductive thematic analysis of interviews was conducted following methods recommended by Graneheim \& Lundman, (2004). This involved familiarisation, identification of meaning units (usually a sentences or groups of sentences that captures a single concept or idea) and assigning each meaning unit a brief heading summarising its meaning in an open coding process. These codes were grouped into higher level categories, clearly rationalising membership of each category in a constant comparison of the categories. Sub themes and themes, that represented the concept underpinning a category or group of categories, were created through a process of abstraction. The initial analysis, creation of categories and themes and overall description of each theme was shared with a panel of qualitative Norwegian researchers to confirm the trustworthiness of the categorisation and abstraction process (Shenton, 2004).

\section{Ethical considerations}

Ethical clearance for this and all work packages of the project was obtained from the Privacy Ombudsman for research, the Norwegian social science data service (NSD) (Ref nr: 39534) and separately from the Director of the Criminal Justice region being investigated (Vår ref: 201313560-5).

\section{Findings}


A wide range of themes emerged from the analysis. In this paper we have chosen to describe four themes that were interrelated and specifically related to collaborative practice and taking responsibility for the care of the offender (see Figure 1). The first theme described MHS and CS leaders' views of what they expected collaborative practice to look like and for responsibility for the care of offender to be distributed between professional groups (theme 1). They then explain how these standard or expected forms of collaborating are mediated by the complexity of these interagency working environments (theme 2), the individual characteristics/structures of the professional engaged in the collaborative practice (theme 3 ) and a range of tensions challenging these collaborative spaces (theme 4).

\section{Expected collaborative practice (theme 1):}

Interviewees describe standard patterns of collaboration: the expected responsibility distribution within and between systems. They discussed how collaborations between the prison and specialist mental health services are expected to function and in the Norwegian prison environment, how the mental health of the offender should be addressed, in the first instance, by the prison nurse who refers on to the prison doctor where necessary. If these professionals believe the mental illness surpasses a particular severity threshold, offenders are referred to specialised mental health professionals from secondary care organisations that visit the prison on a regular basis or alternatively to health professionals outside of the prison with whom the offender may have had contact prior to arrest. If the condition is acute, and specialist professionals are not available on site, the offender is transported out of the prison to specialised mental health services for treatment. Expectations of responsibility taking and reality can differ as illustrated when the MHS and CS negotiate how responsibility for the patient is transferred between prison and specialist mental health staff:

I think if you ask the GP in the prison, he will say that the specialised health services has the threshold to take someone into the specialized service too high... and if they (the offender) come to the specialised service then this might be for a short while, some hours, and then the prisoner is going back to the prison and the prison finds that the treatment they can give is not good enough (Regional Health Lead). 
Deciding which of these professionals, inside or outside of the prison, should take responsibility for the offender is especially important at the beginning of sentence when needs and risk assessments are carried out with the offender and plans made for rehabilitation activity over the duration of their sentence. It is also important when preparing offenders for release and external professionals are engaged in the reintegration process well before the sentence end. Interviewees felt it was important for collaboration between MHS and CS that these divisions of professional responsibilities between and within systems are made clear at these points, although they felt this not always to be the case.

It has something to do with responsibility. No one is responsible. There are so many people and the responsibility is divided. Someone has responsibility for the mental health, someone for housing and they don't speak together (Prison Nurse Lead).

Interviewees assign responsibility primarily by virtue of perceived professional or organisational function and expertise to help the offender. For example, responsibility for diagnosing and providing advice to the prison on the management of acute mental health conditions is assigned to specialised services although nurses talk of their own professional skills and role in providing mental health support.

We are not the experts. They are the experts (referring to specialised mental health services). We need their help. They are experts in their areas (Prison CS Lead).

Within the CS, they describe how different functions are distributed uniprofessionally (e.g. how responsibility for different wings of the prison are distributed between nursing staff) and interprofessionally (e.g. prison nurses are responsible for offenders' health needs and prison social workers for housing or employment needs or different professionals having responsibility for initiating interventions whilst others follow).

So we usually don't initiate. So if they don't have an individualised plan, we usually don't initiate unless we see this is just a mess and we have to do something: if there is something wrong on the outside. If there is a lot of health 
issues meaning drugs, mental heath issues and its just a chaos, and we see that the patient will stay here for a while, we have to work on it. It is usually the social worker who initiates. If someone initiates something, we are then asked if we want to participate in the meeting. (Prison Nurse Lead).

There are examples given of professions sharing responsibility (e.g. the offender's needs assessment being shared between prison officers and prison social workers).

Responsibility is also distributed at an interorganisational level (e.g., in programmes for sex offenders, probation officers recruit to the programme, and the specialised mental health services deliver the programme content).

I think it's that we share responsibility. We don't sit with the responsibility all alone in the prison. We have someone outside to collaborate with and its much easier and we feel that people outside are interested in our inmates (Prison Social Work Lead)

Interviewees described the responsibilities of regional leaders (e.g. disseminating good practice) and the municipality (e.g. initiating an individualised plan- an interagency coordination tool- for the offender). Responsibility is also distributed geographically (e.g. responsibility for mentally ill offenders is distributed between district and regional specialist services dependent on the home municipality of the offender).

I think it is a good thing that the Kommune (municipality) take over. They can be in a kommune far far way and it is not logical that we sitting here should have anything to do with the person outside but I think it could be better if were better at involving the kommune or if the kommune could be better at getting involved (Prison Nurse Lead).

Other responsibilities relate to the need to make referrals at appropriate times, prison officers for example, have responsibility to contact MHS services within a stated time period if an acute mental health issue is suspected. Interviewees also talk of responsibility more generally stating for example, how the municipality needs to take responsibility for the offender before release and the need for prison officers to get involved in the welfare of the offender. 
Responsibilities, that are not treatment related, are described as well: the prison doctor and TFK coordinator role, for example, are described as bridge builders, coordinating relationships between mental health/ other welfare services and prison services at individual and systems levels respectively.

The complexity of external structures (theme 2)

Working together between the MHS and CS is not a straightforward matter but a complex one in which professionals need to negotiate a plethora of many interconnected dimensions. Interviewees describe having to cross multiple boundaries and encountering much contextual variation. This poses challenges related to determining where professional limits lie, finding the right person within the other organisation to take responsibility for the offender and they express frustration when other professionals sometimes fail to take up the responsibility they expect of them. For example, when describing trying to get the municipality involved in the care of a serial and mentally ill offender:

They had all sorts of excuses. They didnt have time. It was inconvenient. All kinds of excuses. So we were disappointed with the community (Prison Social Work Lead).

Interviewees explain how professionals from both health and welfare services, as well as correctional services, negotiate geographical, interorganisational and intraorganisational boundaries when looking for professionals with expertise/capacity to take responsibility for the needs of the offender. They describe how professionals travel across Norway to engage with professionals from different counties, regions and municipalities. They do so to seek out expertise needed to support the offender currently serving sentences or when trying to reintegrate the offender back to their home area when they near release. They seek out the expertise of professionals within their own system or across systems, engaging with a range of public sector (e.g. welfare service, prisons, regional hospital, municipality health services, police) and not-for profit organisations (e.g. Salvation Army). Each of these organisations has additional complexities within their structures caused by divisions into different departments or units, programmes or services, a plethora of official roles and titles and other employment complexities (such as professionals working part 
time between two or more organisations or being paid for by one organisation but located in another). The employment of health staff based in the prisons on a full or part time basis, by the municipality, through the import model of service provision (Norwegian Ministry of Justice and the Police, 2008), is an example of this as is the multi-layered and variable structures within the social security systems (NAV) outside of the prison, an organisation with whom prisons need to collaborate closely when preparing prisoners for release.

The problem in $x$ municipality is that NAV (social security) is very divided, or sectioned....specialist. They often have one saksbehandler (case manager) in economy and one saksbehandler in housing and one in RUS (Drug treatment). So its a lot of people....... So its very difficult for us to find out who is doing what? But in the small community, NAV does everything. One person in NAV can work with economy, with housing, with drugs, so that's much easier...(Prison social work Lead)

Collaborations occur vertically between individuals working at different levels of organisational management (e.g. prison leaders seek advice from regional CS leaders or CS leaders engage with Ministerial bodies) or horizontally across professional boundaries (e.g., psychologists and psychiatrists from specialised mental health services interact with prison officers and lawyers in the CS system).

Finding the right professional to take on responsibility for an offender may also vary depending on the demographical characteristics of the offender (e.g. young offenders, foreign offenders), the location in which their sentence is executed (probation or prison) and/or the offence committed (e.g. sex offenders).

At a national level, Interviewees describe how the health and correctional services divide responsibilities into alternative geographical regions, each with different budgets and laws and managed in different ways. At the municipality level, the distribution of roles, responsibility and key organisational contact points differed from municipality to municipality, reflecting the autonomy of municipalities in Norway, and some municipalities have sizeable offender populations under their jurisdiction whereas others do not. There is further variation at an organisational level between each prison. Prisons are managed 
differently in terms of the number and type of staff employed, the distribution of responsibility between professions as well as in the degree and nature with which state driven interventions are implemented. Interviewees illustrate this variation by referring to the variation with which the TFK coordination role has been introduced nationally, for example.

Added to these structural differences, interviewees describe variations in professionals' knowledge of other organisations and that different groups may hold different values and philosophies towards the offender (e.g. along a rehabilitation versus punishment spectrum). Further, every category of offender (classified by offence for example) and every individual offender has a different permutation of needs.

The variations at national, municipality, personal and organisational levels leads Interviewees to describe their task of seeking out the expertise of other organisations as extremely complex and uncertain. The above complexity creates much variation in the way responsibility is distributed geographically and administratively. This limits the predictability and standardization of collaborative practices between health, welfare and CS systems.

\footnotetext{
I needed them as interview subjects to tell me what happens, what they think of the relationship between the different organisations and the different organisational levels. Prison regions are organized differently from the health regions, from the court regions, so all these regional, municipal and state structures makes it enormously complicated. They have different ways of organizing decision making, budgets and services and knowledge all over the country. I would really want them to tell me as this would really help them and it would help me in my evaluation task (Research leader).
}

\section{Individual structures (theme 3)}

Interviewees generally found it difficult to pinpoint what made a good collaborative worker in this field but if prompted they talked of the characteristics of the individual professional impacting on the quality of the collaboration and whether other professionals took active responsibility for an offender's care. They describe the importance of commitment, personal resolve and passion to bring about change for the offender, as factors that drove 
this. They see positive attitudes towards the offender as a key driver to collaborate, being less likely if the other professional was afraid of, or prejudiced against, working with offenders or a particular group of offenders (e.g. sex offenders). Leaders in the sample believe however that this is changing and that attitudes in the municipality, for example, to offenders have improved over time, that professionals in health and welfare services are more open to working with this group than they have been and that this is due to better preparation in their training.

They have attitudes. Twenty eight years ago, older NAV people were sitting in an office....they were very afraid of prisoners. Now it's more open and the people who work there know a lot about RUS (drugs), about social problems and they can see it as a whole. There is a better understanding that problems when you are young can cause bigger problems when you are older and you have to....to see these things. You can't see a little bit of the person (Prison social work lead).

Interviewees describe the need for professionals to be outwardly facing. This meant the professional should be prepared to reach out actively to engage both with the offender and other professionals or organisations, rather than waiting for the offender or other professional to come to them. It also means that professionals should be open minded to alternative views expressed by other professionals and have the flexibility to take on board alternative ways of doing things that these other professionals may bring to the collaboration.

We focus on understanding each other's role and what they do in their everyday work so that we can understand each other. It's in those morning meetings for example, which is really good. I don't know if other prions do it but the nurses are participating (Prison nurse leader).

Interviewees believe that professionals should be able to see the offender as a whole, linking the many threads of their complex needs. They need to appreciate that developing professional and offender networks takes persistence, optimism and patience and will proceed slowly and incrementally. They need to be assertive in their collaborative dealings standing up for what they believe but exhibiting strong social and relational skills 
when doing so and being strategic in their thinking. They need also to keep up to date in their field but simultaneously know the limits of their professional remit. Much of these skills and knowledge of what works, and what does not, is recognised as coming with a professional's years of experience.

They have to be able to see the whole. They have to be good in their field but at the same time see the whole. They have to...they cant just sit in their office and hope prisoners will knock on their door. They have to go out and find them. Work together with the people working out of the prison.....and find out as much as possible about this inmate. What are his resources and how can he be helped best? (Prison Social work Lead)

Finally, leaders speak of the importance of the professional having a close and personal knowledge of the offender and their history. This is related also to the importance professionals place on the offender being cared for by professionals that know them best, and that transfer to specialist mental health services is not always the answer. They discuss linking offenders to services to whom offenders are already known-their existing professional network as well as their reluctance to refer to specialised mental health services if prison staff can manage the offenders condition adequately themselves.

We try and make an assessment about what they have on the outside ..... if they have a psychiatric doctor on the outside or if we can try an bring their own doctor in, if that is possible...... Usually we have good time to get to know the inmate and get information form the officers about how they interact with the other inmates, how they interact at work, sleep, food. These kind of things. Then we talk to them and try to make to see the whole picture .... We are trying not to hospitalize. We are four nurses here. We are skilled nurses and we have doctor here four times a week, a psychiatrist. We try and use that....to make the best of it in here so that we don't have to...(Prison nurse lead).

Tensions when collaborating across systems (theme 4)

A final theme relates to the tensions when collaborating across systems. A tension identified and relevant to the allocation and acceptance of responsibility across the MHS and CS, related to the challenges of negotiating how responsibility is distributed. 
Interviewees believed that there were several reasons that prevented other organisations or professionals from taking on or fulfilling particular responsibilities related to the offender.

Firstly, the division of responsibility across the multiple levels described is not always clear. Interviewees attribute this partially to the fact that the allocation of responsibility varies between regions, organisations and between municipality (see complexity theme). They perceive this as having two main implications: first this lack of clarity leads to confusion between groups as who should perform a function in any given situation (e.g. should the police or specialised mental health services be responsible for controlling the aggressive behaviours of a mentally ill person in the community; does the offender pass the threshold of mental illness to be referred to specialist mental health services or can the prison doctor, nurse or prison officer manage the condition as effectively?). Second, it also means that professionals, when seeking to create or maintain the offender's support network (both professional and social), find it difficult to identify a named contact within any said organisation to take on the desired support function.

\begin{abstract}
No, it varies from municipality to municipality. So we have to just go that certain to municipality and ask for the drug rehabilitation specialist.. or maybe the GP can help....you were asking who we contact? And the answer is we don't know. We just have to find out because there is no system? (Prison Nurse Lead)
\end{abstract}

The problem in (x municipality) is that the welfare service is very divided, or sectioned, specialist. They often have one case manager in economy and one case manager in housing and one in drugs rehabilitation. So its a lot of people. ...... So its very difficult for us to find out who is doing what? But in the small community, the welfare service (NAV) does everything. One person in NAV can work with economy, with housing, with drugs, so that's much easier...(Prison Social Work Lead)

Interviewees discuss examples of organisations denying responsibility (e.g. mental health services believing the offender to be a drug addiction service problem and vice versa) or in fact denying their own responsibility (e.g. it is not our responsibility to initiate an individualised plan). Similarly they describe organisations as not performing a function the 
Interviewees believed should be assigned to them (e.g. expecting but never seeing an individualised plan for an offender). There is much discussion about a need to get other organisations or a professional group to take responsibility for the offender although the power to enforce this across professional and organisational boundaries is lacking.

We find it is very separated (drug rehabilitation and mental health). We were hoping that the coordination reform would unify them. But we are not seeing that in every day life as much as we were hoping. So often, sometimes we feel that if we... if a doctor.... writes a letter to a rehab policlinic , then they say: "We cant take it, there is too much psychiatric here". On the other hand, the other side says; "There is too much drug issue here" (Prison Nurse Lead).

Secondly, Interviewees believe logistical factors constrain opportunities for collaboration between organisations: incompatible working schedules of professions in each organisation and the geographical distances between the prison on the one hand and community and specialised services on the other, means that building the network of collaborators around the offender is challenging. It is especially so when, for reasons of security, the services are encouraged to come to the prison rather than the offender being transported, at expense, out of the prison.

Across the board, limited human resources limit the capacity of organisations to engage in the collaborative tasks of mapping and addressing offenders' needs. So in prisons only the most needy receive a full needs assessment because of the limited number of staff available to perform this role. Similarly limited capacity in the police force may restrict the number of offenders in custody that can be transported from prison to specialized mental health services in the regional hospital or the municipality may not be able to release staff to come to the prison to address the needs of a particular individual. Other resource issues include limited housing places in the municipality, limited beds in community services, the need to make savings in current times of austerity, no service at all in the home area of the offender and the fact that offenders needs are complex and addressing these is cost intensive. These lack of resources means that opportunities for collaboration are lost. 
Overall leaders describe professionals as having to rely heavily on their own professional judgements to understand their own roles and responsibilities and that of other professionals working within the same or other organisations.

\section{Discussion}

Stones (2005), building on Giddens' (1984), concept of structuration, seeks to explain the relationship between structure and agency: the interplay between the real world and social structures external to us and the impact this has on our individual ability to act. The agent is the individual or individuals engaging in a particular activity or task. In this paper the agent in focus is the professional from the correctional or health service and the activity explored is the collaboration between professionals from the same or other system. Collaboration, as an activity in general, was a concept our interviewees found difficult to articulate and they focused instead on one key dimension of this, namely the action of a professional or organisation assigning or accepting responsibility for the care of the mentally ill offender. They describe this activity in terms of how they perceive responsibility for the offender to move, or be shared, between the MHS and CS (see theme 1 Figure 1).

In describing this activity, they indicate that this dimension of collaborative practice is more complex than suggested by the following definition of collaborative practice, "when multiple health workers from different professional backgrounds provide comprehensive services by working with patients, their families, carers and communities to deliver the highest quality of care across settings" (World Health Organisation, 2010, p13). The collaboration in the MHS/CS context is more than between health professionals; it involves prison officers, prison social workers, the police as well as psychologists, psychiatrists and many others. Expertise is distributed across a range of organisations, levels and professions. The type of collaboration described is less in keeping with traditional views of stable team working but more in line with the concept of co-configuration in which the expertise to help the offender rehabilitate is distributed across a range of loosely connected professionals from a range of organisations who are required to collaborate over an extended periods of time to support the needs of the offender as they progress through the correctional services (Daniels, Leadbetter, Warmington, Edwards, et al., 2007). This distributed expertise is typical in many health and welfare environments: Edwards (2011) for example describes similar phenomenon and challenges in education, 
where school welfare managers access the expertise of multiple external organisations to address the needs of children in danger of social exclusion.

Structuration theory predicts that the collaborative activity described by MHS and CS leaders will be constrained or facilitated by external structures. The complexity theme (Theme 2 Figure 1) describes some of these external structures that mediate the collective action (Stuart, 2014) of assigning and accepting responsibility for the care of the offender (e.g. the organisation of services regionally and nationally). Leaders describe these structures as multi-dimensional, highly varied and to combine in multiple permutations. This complexity of these external structures means MHS and CS professionals must cross multiple boundaries created by geographical distribution of services as well as intra and interorganisational borders. The Interviewees' demarcation of boundaries between units is a generic feature of the collaboration process, being described in other contexts as a first step in boundary crossing (Akkerman \& Bakker, 2011). This is described by Engeström, Engeström, \& Kärkkäinen, (1995) as a form of polycontextuality, in which professionals cross boundaries of demarcated expertise to engage with multiple communities of practice.

Collaboration between the criminal justice and mental health systems is influenced by structures external to the agent but is influenced by structures internal to them also (See Figure 1, theme 3). Internal structures have two components: Bourdieu's (1986) concept of habitus of the agent and knowledgeability that the agent has of external structures surrounding them. Habitus describes the predispositions, history, social and human capital distinct to each individual and that constrains or facilitates their actions (Stones 2005). In this study, the internal structures, impacting on the way professionals take or assign professional responsibility, is described in theme 3 (See Figure1) and the characteristics of the individual professional suited for collaboration (e.g. being outwardly facing). These features mediate the likelihood that professionals will effectively cross inter and intra organisational boundaries, described in theme 2 , required to negotiate who should take responsibility for the offender, when and how they should do this.

Finally, although initially constrained by external and internal structures, collaborative practice between the MHS and CS, is further constrained by key tensions within the interactions (that include lack of clarity on responsibility, logistical and resource limitations 
(see Figure 1 theme 4). The complexity of working environments contributes to the lack of clarity on responsibility taking described.

All four of the themes may interact to dictate how individual professionals and organisations effectively engage and take responsibility for the support of an offender and how this responsibility taking is negotiated between professionals across the MHS and CS boundary (see Figure 1). In other words, the way that responsibility is distributed between organisations and professionals is a product of the complexity of the external structures surrounding this practice, and typical of any complex open system (Kernick, 2003). It is feature also of the internal structures of individual professionals engaging in this collective activity as well as a range of tensions within the system. Combined these create an environment in which stakeholders, engaged in collaborative activity between the MHS and CS, may not take on responsibility for the offender as expected (Figure 1) which is reflected by interviewees when they describe the unpredictable and changeable practice context, where they must rely heavily on their own professional judgements to understand their own roles and responsibilities and that of other professionals working within the same or other organisations. This is recognised as a key characteristic of interprofessional and interagency collaboration in other contexts also (Ødegård, 2006; Atkinson, Doherty, \& Kinder, 2002). In some health care contexts there will be routinized procedures (Akkerman and Bakker, 2011) or standardised care pathways that will make this decision making clear cut: that lays out who is responsible for what task and when. However, in this MHS/CS context, and in Norwegian health and welfare contexts in general, these structures are often vague, lacking routinized procedures about whom to involve and when (Willumsen \& Skivenes, 2005). In fact, the individual and changing needs of offenders represents a particular challenging or 'wicked problem' that resists standardisation or the formulation of standardised treatment pathways (Rittel \& Webber, 1973).

\section{INSERT FIGURE 1 ABOUT HERE}

\section{The way ahead}

There will be various approaches to improve collaborative activity in the MHS and CS context in the future. A focus on improving external structures is one, but the challenges that face standardisation of these in this complex environment, means that a focus on internal structures instead may have more traction. Stones (2005), in his description of 
internal structure influences, describes a knowledgeability dimension which he defines as the awareness by the agent of the external structures that surround them and their ability to work within these. The more awareness they have of the external structures around them, it is hypothesized that the more likely it is that there will be fewer unintended consequences of the agents action. This is a key competence required to work collaboratively and a competence related to making decisions about assigning and taking responsibility.

The importance of the dimension is partially reflected in the specific role and responsibility domain within some collaborative competency frameworks. The Canadian National Collaborative competencies framework, for example (Orchard \& Bainbridge, 2010) describes a range of competence domains (interprofessional communication, patient/client/family /community-centred care, role clarification, team functioning, interprofessional conflict resolution and collaborative leadership). Focusing on the role clarification domain, this competence is an ability to articulate one's own role and the roles of other professions, understand how these complement one another, and use this knowledge to treat the patient holistically. Similarly, the Interprofessional Education Collaborative (2011) competency framework describes a role and responsibilities domain as the ability to, "use the knowledge of one's own role and those of other professions to appropriately assess and address the healthcare needs of the patients and populations served" (p.21). It reiterates the need to communicate one's own professional responsibilities to others, to understand those of other professions, knowing where professional limitations lie and being able to develop and manage the interdependent relationships between the diverse professionals and skills available.

What is described in the roles and responsibility competence domains above (Interprofessional Education Collaborative, 2011; Orchard \& Bainbridge, 2010) is what Miller, (2001) describes as the principle of professional capacity. In other words, professionals, when looking to assign responsibility for a dimension of offender care, decide which professional is best qualified in terms of professional skill to help the vulnerable individual. Our Interviewees take this approach when describing which professionals and organisations have responsibility for what offender need in theme 1 . For example, the psychiatrist is best placed to treat mental illness. However, there are other principles at play as Miller (2001) suggests that, although a professional may have 
the capacity in terms of training, to take on a particular responsibility, the cost to the individual professional to perform this task may be too great. A prison social worker may believe, for example, that a municipal worker has the capacity (in term of training and role) to address an offender's future sheltered housing needs, but personal, logistical and resource costs to that professional and their organisation may make meeting these obligations impossible. Weighing cost versus capacity is an important skill for the professional in order to understanding role and responsibility dimensions of collaboration. They need to demonstrate what Edwards, (2011) describes as relational agency and Akkerman \& Bakker (2011) as perception making: the action of understanding the practice of another group, the ability to understand the constraints and priorities placed on another agent and their ability to adapt their own behaviour accordingly. Leaders, when discussing key tensions in the system (theme 3 Figure 1) that they believe leads to other professionals not engaging in collaboration, demonstrates an element of this ability.

In addition to capacity and cost, Miller (2001) describes a third communitarian principle applicable to negotiating interagency collaboration. This relates to the strength of the social ties held by the person in need. It is the responsibility of those actors with the closest relationship to the person to take action rather than those unknown to them. In our study this relates to the social ties of the offender discussed by Interviewees in the internal structures theme 3 and of the individual characteristics of the individual professional impacting on the quality of the collaboration. A prison nurse or prison officer, for example, may have less capacity (in terms of experience or training) to treat the mental health of the offender if compared to the psychiatrist in specialised mental health services but they have responsibility because they are better known to the offender. Depending on the mental health condition, this communitarian link with the prison officer may outweigh the higher skill capacity of the specialised services, when decisions are made about who takes responsibility for supporting the offender. This is in keeping with Appelbaum, Hickey, \& Packer (2001) and Dvoskin \& Spiers (2004) who explore the multiple ways in which prison officers can serve both as therapeutic agents in crisis intervention, prevention and the delivery of on going psychotherapy, sometimes in ways that are more effective than that provided by mental health specialists. It is also in line with the principle of lowest effective level of care that predominates in the Norwegian health and social care system (Nylenna \& Larsen, 2005). In this context, the prison officers may in certain circumstances be both the lowest level of mental health care and also the people that know the offender best. 
Miller (2001) argues that in assigning or distributing responsibility described, the principles (we discuss capacity, cost and communitarian principles in this article) cannot be considered independently, but should be viewed pluralistically, weighing one way up against the other, before responsibility is assigned. We believe that all these principles should also be included in the roles and responsibility domain of collaborative competency frameworks, rather than the capacity dimensions alone, as is currently the case. A balance is required. Every collaborative situation will be different, complex and unpredictable and the responsibility of educators is to provide students with the skills that enable them to make these judgements and to understand the range of factors that influence who is best placed to support an offender. Collaborative competence frameworks need to be expanded beyond simply understanding responsibility in terms of the functions that other professions perform in relation to one's own. Students need also to explore the costs of the most skilled professional, such as the psychiatrist, taking on responsibility and providing treatment, and recognise those circumstances in which those who know the offender (such as the prison nurse or prison officer) may be better placed to take responsibility. They need also to consider the organisational resources and individual characteristics of the other professional when assigning responsibility for care to them.

The study has its limitations that should be taken into account when considering its findings. Although the interviews provided in depth data, the size of the sample is a small one, confined to one region of Norway that will raise concerns of the transferability of these findings. Following analysis it became evident that, whilst municipality staff had been represented in the sample (the prison nurse), the voice of municipal workers based outside of the prison were missing and in retrospect important for better understanding this complex field. Further, although the level of spoken English was very high, the Interviewees may still not to have been able to articulate their opinions to the same degree as if the interviews had been done in their native language. Although native Norwegians were involved in both the interviews and validation of the analysis, language and outsider status of the first author and main interviewer will have affected the nature of the data collected. Lack of cultural familiarity will have offered the first author both novel insights into collaborative practice in the region, but may also have lead to a misinterpretation or failure to pick up relevant cues during the interview and analysis process. Finally the concept of collaboration is an intangible one that Interviewees often struggle to articulate. 
Interview schedules should focus in the future on more specific activities (that required collaboration) rather than about collaboration directly, to achieve greater understanding of how collaborative practices in this context function (Engeström 2001)

\section{Concluding comments}

In this study, we explored collaborative practice between mental health and correctional services in a Norwegian context. We find that leaders are exercised by one dimension of collaborative practice in particular, namely the distribution of responsibility for the care of the offender across systems. This activity is mediated by highly complex external structures as well as the individual characteristics of the professionals involved. Professionals and organisations who fail to take responsibility for the offender as expected, may be constrained from doing so by resource limitations, logistical issues and poor attitudes towards the offender population.

Based on these findings, the paper suggests that the MHS and CS workforce would benefit from a great knowledgeability of the roles and responsibility domains of collaborative practice. However, competency frameworks are currently limited, focusing on a capacity dimension of responsibility assignment that articulates and interrogates one's own responsibility and that of others as a trained professional. Whilst this is important, it is more complex than this. Students should be encouraged also to consider the cost for other professionals taking up particular responsibility. They should be given the opportunity to weigh up Miller's principles of assigning responsibility, one against the other, exploring the tensions and limitations of the other professional, as well the position of the professional relative to the offender, when negotiating with other professionals and organisations as to who has responsibility to alleviate the suffering of this target population group.

\section{Acknowledgements}

We acknowledge the extensive contribution of professionals in the Norwegian correctional and specialised mental health services to this study.

\section{Declaration of interest}


The authors report no conflicts of interest. The authors alone are responsible for the content and writing of this article.

\section{Funding}

This study is funded by the EU Commissions FP7 Marie Curie Intra European Fellowship funding scheme (FP7-PEOPLE-2013-IEF 628010)(2014-2016)

\section{References}

Appelbaum, K. L., Hickey, J. M., \& Packer, I. (2001). The role of correctional officers in multidisciplinary mental health care in prisons. Psychiatric Services, 52(10), 1343-1347.

Armstrong, S. (2012). Reducing Reoffending: Review of Selected Countries, Edingburgh: Scottish Centre for Crime and Justice Research.

Atkinson, M., Doherty, P., \& Kinder, K. (2002). models , challenges and key factors for success. Journal of Early Childhood Research, 3(1), 7-17.

Bond, B. J., \& Gittell, J. H. (2010). Cross-agency coordination of offender reentry: Testing collaboration outcomes. Journal of Criminal Justice, 38(2), 118-129.

Bourdieu, P. (1986). 'The Forms of Capital'. in Handbook of Theory and Research for the Sociology of Capital. J. G. Richardson. New York, Greenwood Press: 241-58.

Brandt, B., Lutfiyya, M. N., King, J. a, \& Chioreso, C. (2014). A scoping review of interprofessional collaborative practice and education using the lens of the Triple Aim. Journal of Interprofessional Care, 1820, 1-7.

Chang, Z., Larsson, H., Lichtenstein, P., \& Fazel, S. (2015). Psychiatric disorders and violent reoffending: a national cohort study of convicted prisoners in Sweden. The Lancet Psychiatry, 0366 (15), 1-10.

Friestad, C. \& Kjelsberg, E. (2009). Drug use and mental health problems among prison inmates--results from a nanation-wide prison population study. Nordic Journal of Psychiatry, 63, 237-245. 
Dvoskin, J. A., \& Spiers, E. M. (2004). On the role of correctional officers in prison mental health. The Psychiatric Quarterly, 75(1), 41-59.

Edwards, A. (2011). Building common knowledge at the boundaries between professional practices: Relational agency and relational expertise in systems of distributed expertise. International Journal of Educational Research, 50(1), 33-39.

Engestrom Y. (2001). Expansive learning at work: towards an activity theoretical reconceptualisation. Journal of Education and Work, 14, 133-156.

Engeström, Y., \& Sannino, A. (2011). Boundary Crossing and Boundary Objects. Journal of Organizational Change Management, 24(3), 368 -387.

Giddens, A. (1984). The constitution of society: Outline of the theory of structuration. Cambridge: Polity Press.

Graneheim, U. H., \& Lundman, B. (2004). Qualitative content analysis in nursing research: Concepts, procedures and measures to achieve trustworthiness. Nurse Education Today, 24(2), 105-112.

Interprofessional Education Collaborative. (2011). Core Competencies for Interprofessional Collaborative Practice: Report of an expert panel,. Washington D.C.: Interprofessional Education Collaborative.

Justice Cooperation Network. (2011). Development of minimum standards and best practice model. Accessed 01.01.2016; Retrieved from http://jcn.pixelonline.org/files/workshops/04/01_English version.pdf

Kernick, D. (2003). Can Complexity Theory Provide Better Understanding of Integrated Care? Journal of Integrated Care, 11, 22-29.

Kristoffersen, R. (2013). Correctional Statistics of Denmark, Finland, Iceland, Norway and Sweden 2008 - 2012. Oslo: KRUS

Miller, D. (2001). Distributing Responsibilities*. The Journal of Politial Philosophy, 9(4), 453-471.

Ødegård, A. (2006). Exploring perceptions of interprofessional collaboration in child 
mental health care. International Journal of Integrated Care, 6(December), e25.

Orchard, C. A., \& Bainbridge, L. A. (2010). A National Interprofessional Competency Framework. Vancouver: Canadian Interprofessional Health Collaborative.

Patton, M. Q. (2002). Qualitative research and evaluation methods (3rd ed.). Thousand Oaks, CA US: Sage.

Rittel, H. \& Webber, M, (1973) Dilemmas in a General Theory of Planning Policy Sciences, 4, pp. 155-169,

Sapouna. (2015). What works to reduce reoffending: a summary of the evidence. Edingburgh: Justice Analytical Services Scottish Government

Shenton, A. (2004). Strategies for ensuring trustworthiness in qualitative research projects. Education for Information, 22, 63-75. doi:10.1111/j.1744618X.2000.tb00391.x

Skeem, J., \& Peterson, J. (2011). Major Risk Factors for Recidivism Among Offenders with Mental Illness. Report prepared for the Council of State Governments (CSG). Accesed 01.01.2016; Retrieved from http://riskreduction.soceco.uci.edu/index.php/publications-all/published- riskassessments/

Sverdrup, S. (2013). Evaluering av tilbakeføringskoordinatorene : analyse av implementeringsprosessen. Oslo: Hogskolen Diakon.

Vangen, S., \& Huxham, C. (2013). Building and using the theory of collaborative advantage. In R. Keast, M. Mandell, \& R. Agranoff (Eds.), Building and Using the Theory of Collaborative Advantage. In Network Theory in the Public Sector: Building New Theoretical Frameworks. New York, NY: Taylor and Francis.

Willumsen, E., \& Skivenes, M. (2005). Collaboration between service users and professionals : Legitimate decisions in child protection - a Norwegian model Correspondence.Child and Family Social Work, 10, 197-206.

World Health Organisation. (2010). Framework for Action on Interprofessional Education \& Collaborative Practice. Geneva: WHO. 
Zwarenstein, M., Goldman, J., \& Reeves, S. (2009). Interprofessional collaboration : effects of practice-based interventions on professional practice and healthcare outcomes Cochrane Database Syst Rev. Jul 8;(3):CD000072.

1

2

3

4

5

6

7

8

9

10

11

12

13

14

15

16

17

18

19

20

21

22

23

24

25

26

27

28

29

30

31

32

33

34

35

36

37

38

39

40

41

42

43

44

45

46

47

48

49

50

51

52

53

54

55

56

57

58

59

60 